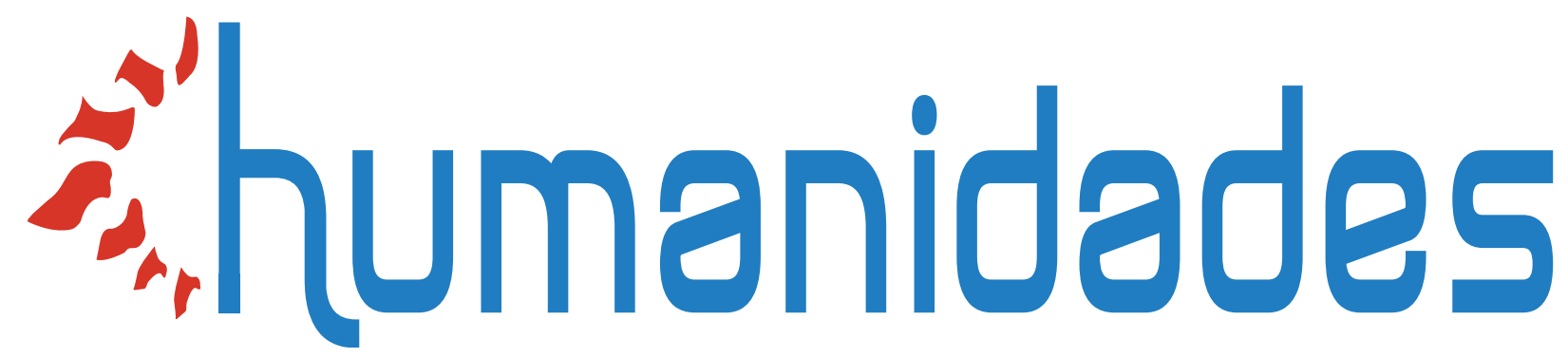

\title{
Correspondencias entre música y palabra, un introspectivo viaje sinestésico entre ambas
}

\author{
Susana Rodríguez Pendás
}

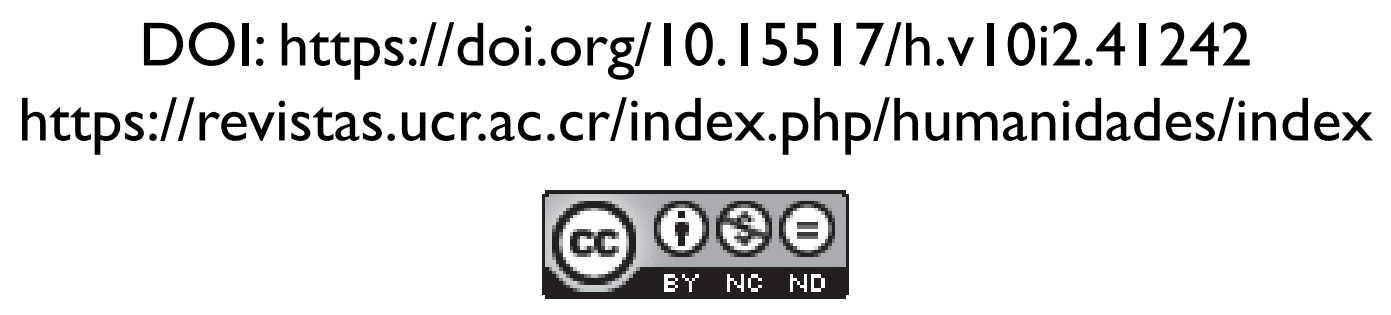

Universidad de Costa Rica 


\title{
"humanidades
}

Revista Humanidades

ISSN: 2215-3934

humanidades@ucr.ac.cr

Universidad de Costa Rica

Costa Rica

\section{Correspondencias entre música y palabra, un introspectivo viaje sinestésico entre ambas}

\author{
Rodríguez Pendás, Lic. Susana \\ Correspondencias entre música y palabra, un introspectivo viaje sinestésico entre ambas \\ Revista Humanidades, vol. 10, núm. 2, 2020 \\ Universidad de Costa Rica, Costa Rica \\ Disponible en: http://www.redalyc.org/articulo.oa?id=498062469005 \\ DOI: https://doi.org/10.15517/h.v10i2.41242
}

Esta obra está bajo una Licencia Creative Commons Atribución-NoComercial-SinDerivar 3.0 Internacional. 


\title{
Correspondencias entre música y palabra, un introspectivo viaje sinestésico entre
} ambas

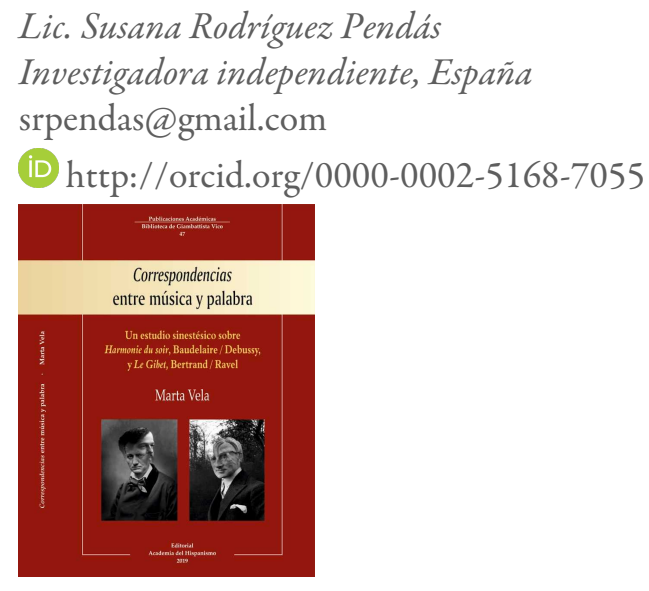

\author{
DOI: https://doi.org/10.15517/h.v10i2.41242 \\ Redalyc: http://www.redalyc.org/articulo.oa? \\ $\mathrm{id}=498062469005$
}

Vela Marta. Correspondencias entre música y palabra: Un estudio
sinestésico sobre Harmonie du soir, Baudelaire/Debussy y Le Gibet,
Bertrand/Ravel. 2019. Vigo. Editorial Academia del Hispanismo.
$148 \mathrm{pp}$.

Syn [juntos] y aesthesis [sensación], (sinestesia) unidos en un delicado y profundo estudio sobre la íntima y compleja relación existente entre música y palabra, sin duda es un entramado sinestésico y una constante a lo largo de nuestra historia. Con este origen griego del término, la autora nos traslada a "los remotos inicios de la estirpe humana" (Vela, 2019, p. 15) para entender de qué manera la música y la literatura han caminado de la mano complementándose, contrastándose e, incluso, distanciándose la una de la otra.

Los antiguos griegos entendieron la perfección de la tragedia a través de la triúnica choreia, entendida como una excelsa unión entre danza, poesía y música que la humanidad ha ido entrelazando y tejiendo, a saber, de diferentes procesos. Es decir, culminando, tal vez, en la Gesamtkunstwerk [obra de arte total] que Wagner concibió como una renovación transfigurada del arte musical antiguo. Si la música no podía comunicar nada en concreto, al contrario que la literatura, era porque su forma de expresión trascendía el lenguaje común y podía ser capaz de captar, con inigualable profundidad, la esencia del ser humano y todos sus entornos, tanto terrenales como espirituales, gracias a un código de sonidos enigmático y clarividente a una misma vez (Vela, 2019, p. 19).

\section{Breve PERSPECTIVA Histórica}

Hasta que el género instrumental, tímidamente en los albores del siglo XVII, surgiera como tal, propiamente dicho, la música había sido mero vehículo transmisor y soporte a su vez de la palabra. La música religiosa, y la profana en menor medida, habían cautivado sin duda alguna la escucha humana al aportar al texto su "manifiesta semanticidad" y dotar a la música de un gran contenido artístico.

Asimismo, Josquin Desprez (1450-1521) al dejar atrás la varietas, con un sinfín de melodías continuas, logra una excelsa simplificación musical a través del desarrollo temático por medio del motete imitativo y su soggetto [sujeto], este como una combinación de intervalos y giros melódicos que describen al texto que acompañan. Más adelante, Gesualdo, Caccini, Monteverdi tomarán en herencia esta idea y la utilizarán a través del madrigalismo, el cual es un motivo también descriptivo utilizado para ensalzar la expresividad de la poesía. Años más tarde sería retomado y reconvertido por Berlioz, en su ideé fixe, y por Wagner, a través del 
leitmotiv ${ }^{1}$. Estas ideas de Wagner fueron una gran influencia en los compositores de fin de siècle, todo ello pese a sus contradicciones y sin escapar de las críticas ${ }^{2}$, los cuales avivaron así la disputa entre absolutistas y referencialistas, que resultaría suavizada con la llegada de la atonalidad y otros géneros musicales que ponen nuevamente en entredicho la semanticidad de música y palabra.

En el profundo análisis efectuado por la autora, nos encontramos ante la dualidad de la música absoluta o pura, entendida como arte inasible, intraducible en palabras, capaz en sí misma de llevar a nuestro ser a lo absoluto, más allá de la voluntad, sin necesidad de palabras, ni de estímulos extramusicales, ni de la música programática, aquella que sí está inspirada en algo exterior, como un poema o un paisaje. Música con estímulos extramusicales que encuentra un pasado en Vivaldi, baste de ejemplo Le quatro stagioni [Las cuatro estaciones] (1719) cuya inspiración son cuatro sonetos uno por cada concierto, atribuidos al propio Vivaldi. Otro ejemplo es Haydn, a través de Die Schöpfung [La Creación] (1796-98), en esta obra es la biblia quien guiará la concepción de esta. Pero, sin duda, la más famosa obra programática antes del período romántico es la Sinfonía Op.68 "Pastoral" de Beethoven ${ }^{3}$.

Todo ello nos lleva al poema sinfónico que Liszt ideó como forma de escapar de su “agotada” forma sonata, inspirándose en ideas observadas en Francia, una simbiosis entre música y palabra enraizada a las corrientes racionalistas y a la tendencia cartesiana. Por tanto, la Gesamtkunstwerk supone la culminación de la tragedia griega, transformándola y transfigurándola de forma que todas las artes (humanas y plásticas) estén al servicio del drama.

\section{LA CUESTIÓN DE LA SEMANTICIDAD}

El lenguaje musical y el poético o literario fluyen por caminos diferentes de expresión. Ambos se ansían mutuamente, música y poesía a la par que se contradicen. El lenguaje literario se nutre del lenguaje cotidiano (medio de comunicación entre personas que lo conocen y comparten), para transcender y superar su significado coloquial a un mensaje expresivo "de naturaleza artística" (Vela, 2019, p. 31).

Por el contrario, la música, con un lenguaje no de dominio público, ofrece un significado simbólico, un lenguaje subjetivo, por tanto, resulta la más asemántica de las artes. Motivo por el cual, para la autora, la poesía ha buscado esa "asemanticidad" de la que hace gala la música. A su vez, la música ha perseguido la significación de la palabra, con ello, hace un análisis y reflexión de cómo "la tarea de semantización de la música es harto complicada" (Vela, 2019, p. 34). La música se compone de pequeñas unidades mínimas (fonemas, motivos, notas) unidas unas con otras que forman frases con un concepto mayor y lingüístico identificado por Saussure ${ }^{4}$ : "quedando así el discurso musical como un sistema organizado de expresión carente de significado literal, sujeto entonces, a una significación polivalente o ambigua” (Vela, 2019, p. 42). Todas estas ideas nos ayudan a comprender a la música desde una perspectiva tridimensional, con un significado que está sujeto a la individualidad del compositor y a la perspectiva de quien la escucha, lo cual resulta en ser un arte influenciado por los conceptos históricos y estéticos de cada época pero que a la vez resulta atemporal.

Se entiende la sinestesia como una metáfora entre correspondencias artísticas. Un contexto en el que las diversas experiencias sensoriales buscan y hallan un punto de encuentro. Por un lado, un texto poético se puede percibir a través del discurso musical; por otra parte, la música es inspirada por la poesía y nos remite a un texto inicial. La autora considera dichas relaciones como algo bidireccional, cerrado sobre sí mismo. Algunos compositores y poetas buscan la forma de facilitar esta correspondencia, a través del estímulo de sentidos diferentes: saborear un texto, oler colores, escuchar un cuadro, entre otros. Siendo ya elucidado en el siglo XIX por Baudelaire ${ }^{5}$, en su soneto Correpondances (cuarto poema de "Les Fleurs du mal", 1857), "se abordaba la cuestión de la sinestesia como correspondencia entre las artes a través de lo simbólico" (Vela, 2019, p. 43). 


\section{CORRESPONDENCIAS: ESTRUCTURAS Y PROCESOS COMPARTIDOS}

Al quedar claras las íntimas relaciones que música y palabra han mantenido a lo largo del tiempo, determinadas correspondencias son trasladadas en sentido bidireccional, así pues, se someten a "un cauce temporal determinado, inexistente en otras ramas artísticas como la pintura o la arquitectura” (Vela, 2019, p. 46).

El texto y su estructura aportan al compositor un comienzo para su concepción sonora, la cual se puede llevar a cabo fielmente o recorrer senderos expresivos abiertos a nuevas posibilidades sonoras. La autora refuerza su exhaustivo estudio con claras referencias a textos de Müller, Petrarca, Shakesperare, Tolstói, Rubén Darío a la par que ejemplifica con obras de Mozart, Beethoven, Berlioz, Ravel, Schubert, Schumann o Tchaikovsky; pero es en Debussy a través de su obra Prélude à l'après-midi d’un faune (1892-1894), basada en la obra literaria homónima creada por Mallarmé, donde se encuentra un minucioso y exquisito análisis de ambas obras.

Además, se pueden observar las correspondencias entre el ritmo estructural y la forma, puesto que los elementos discursivos generan cierta tensión hasta culminar en un clímax, el cual liberará su energía al final de la obra y se erige a su vez como punto de partida; todo ello guiado por proporciones áureas y la serie de Fibonacci. Todas estas conexiones entre música y palabra serán llevadas a cabo por compositores posteriores -Bartók, Webern o Varèse-, al igual que parte de la vanguardia musical acontecida a partir de 1945.

Una selección de motivos y su combinación ${ }^{6}$, unido a un principio compartido de carácter dual "repetición/variación" aplicable tanto a la música como a la poesía, supone una "herramienta de coherencia interna" y un "flujo de sus respectivos discursos" en palabras de la autora. Es por ello que el desarrollo motívico-temático tendrá una correspondencia con la interacción morfológica del texto y su expresión, según su articulación dramática:

Un tema de oposición interior encierra en sí dos ideas musicales de marcado dualismo forma-según las premisas del eje de combinación-, reflejando una dimensión, asimismo, antagónica, a niveles formales superiores- por ejemplo, entre la primera y la segunda área tonal de la sonata, entre la exposición y la recapitulación, etc. (Vela, 2019, p. 56).

Las emociones percibidas y transmitidas a través de la música son aprehensibles desde nuestra intuición, por ello con "las atmósferas sonoras inesperadas por un texto de carácter físico o espiritual” (Vela, 2019, p. 70) emerge una nueva una visión de correspondencia entre música y palabra. La utilización de recursos sonoros descriptivos y onomatopéyicos cierran esta parte en la que la autora analiza obras como el segundo poema del ciclo Die schöne Müllerin (1823) [La bella molinera] de Schubert, acá se observa una clara identificación entre el protagonista y el arroyo; o el Soneto 104 de Liszt, concebido sobre el homónimo texto del Canzoniere de Petrarca (en torno a 1327). La armonía, a su vez, permite múltiples combinaciones dentro de nuestras leyes tonales ${ }^{7}$, en símil a la sintaxis. Así pues, la cadencia supone una articulación del discurso musical.

\section{LA SINESTESIA COMO SÍMBOLO COMÚN}

Para la autora, las relaciones sinestésicas (música y poesía) resultan muy productivas en el seno de la cultura francesa, motivo por el cual el interesante y profundo análisis de cuatro obras (dos literarias y dos musicales) pondrán final al libro. Harmonie du soir es el poema número cuarenta y tres de "Les Fleurs du mal" de Baudelaire junto al preludio número cuatro (basado en la impresión de la obra literaria) Les sons et lesparfums tournent dans l'air du soir, recogida en "Préludes I" (1909) de Debussy. Además, Le Gibet, es uno de los textos del poemario "Gaspard de la nuit" (1836) de Bertrand, siendo publicado a título póstumo y la obra musical homónima Le Gibet de Ravel. Como se puede observar, la obra presenta a cuatro artistas coincidentes en tiempo. Por un lado, los escritores Bertrand y Baudelaire con dos poemas fronterizos entre el romanticismo 
y las corrientes finiseculares, por el otro, los compositores Debussy y Ravel, renovadores del estilo musical de su época en post de las tendencias innovadoras del fin de siècle.

En Harmonie du soir, uno de los textos sinestésicos por excelencia del autor (inspirado en Madame Sabatier, una de sus amantes), utiliza una serie de versos de origen malayo, que agrupa en quatrains [cuartetos] estructurados en forma circular, sirviéndose de las características que le interesan:

Elaborando así una suerte de faux pantoum en el que, contra la forma tradicional utiliza el verso alejandrino (en Francia doce sílabas y no catorce como en la literatura hispánica), en lugar del octosílabo o el decasílabo, la rima abrazada, en vez de cruzada (Vela, 2019, p. 86).

El ritmo regular propiciado por la rima, unido a la longitud del verso, se confronta con una reiteración alterna de los versos repetidos, combinados en cada quatrains con otros diferentes. Observa la autora como Baudelaire aporta un nuevo enfoque estético en su poesía, pues recrea una atmósfera que permite el surgimiento de la belleza desde la verdad cotidiana. Debussy recogerá dicha impresión exquisitamente a través de su música con una armonía ambigua, se aleja de forma sutil de la tonalidad y otorga así una sonoridad tan voluptuosa como crepuscular. El compositor se basa en la forma de preludio y de esta manera le permite la libertad adecuada para captar la esencia del poema.

En "Gaspard de la nuit" (1836), Bertrand utiliza el género poema en prosa, técnica que resultará muy importante para las corrientes finiseculares, sobre todo, a partir de este poemario, de gran influencia para Baudelaire y Mallarmé. Una de las herramientas más importantes a nivel expresivo del poema de Bertrand es una compacta organización sintáctica que presenta una calculada curva de tensión dividida en tres partes iguales. Ravel toma contacto en torno a 1896 con el poemario de Bertrand, al que decide recrear musicalmente, a través de una suite de piezas para piano que completaría sobre tres fragmentos: Ondine, Le Gibet y Scarbo. En Le Gibet se hallan grandes similitudes con el texto de Bertrand, una estructura tripartita sobre otra cíclica. Una muestra, sin duda, del gusto del compositor por las correspondencias que la autora analiza hasta el más mínimo detalle.

\section{ConCLusión}

La obra es un estudio minucioso y completo, un exquisito análisis sinestésico entre música y poesía, donde la autora aporta grandes materiales que permiten una clara comprensión de lo expuesto en el mismo. Asimismo, nos encontramos ante un libro muy útil de consulta, con gran variedad de anexos, los cuales expresan de forma clara y concisa lo explicado a lo largo de toda la obra que resulta de sencilla comprensión. Sin duda, música y poesía se han entremezclado a lo largo de la historia, denotando influencias y contraposiciones entre ellas dando como resultado unas exquisitas correspondencias.

\section{REFERENCIAS}

Vela, M. (2019). Correspondencias entre música y palabra: Un estudio sinestésico sobre Harmonie du soir, Baudelaire/ Debussy y Le Gibet, Bertrand/Ravel. Vigo: Editorial Academia del Hispanismo.

\section{Notas}

1. Motivo conductor, melodía o idea fundamental de una composición musical que se va repitiendo y desarrollando de distintas formas a lo largo de toda la composición, identificando situaciones, personajes, sentimientos entre otros.

2. Johannes Brahms, fue considerado en su tiempo como la parte opositora a la música programática "Liszt- Wagner". Salvador del género instrumental, heredero de las formas clásicas como la forma sonata y por ende con inspiración en Beethoven, a partir de lo cual construyó un legado musical con gran originalidad. Así lo podemos observar en sus obras: 
Primera Sinfonía en Do menor, op.68 (1862-1876), Segunda Sinfonía en re mayor, op.73 (1877), Tercera Sinfonía en Fa mayor, op.90 (1883) y Cuarta Sinfonía en mi menor, op.98 (1884).

3. Estrenada en Viena el 22 de diciembre de 1808 y subtitulada como Recuerdo de una vida campestre, con procedencia popular de algunos de sus temas.

4. Saussure, en el Curso de Lingüistica general, publicado en 1916 por sus alumnos. Considerando que la identidad entre significante y su significado era inasumible por la música, pues toda tentativa de trasladar un referente fijo al discurso sonoro estaría abocada al fracaso.

5. Uno de los acérrimos defensores de las ideas wagnerianas en Francia.

6. Según el axioma de oposición binaria enunciado por Ruwet (1972, p. 100).

7. Podemos considerar la armonía como un método análogo al de la sintaxis, dado que también permite combinaciones ilimitadas dentro de las leyes tonales establecidas por la acústica, a saber, la resolución de la disonancia en consonancia la relación de tensión entre tónica y dominante, la cadencia como articulación del discurso, los métodos de modulación, a tonos vecinos o alejados, y el marco fundamental de la tónica como comienzo y final de la obra (Vela, 2019, p. 68).

\section{BY-NC-ND}

